\title{
Major depressive disorder and delirium caused by antidepressant discontinuation in elderly patients
}

\author{
Lee-Hou Tsal ${ }^{1}$, Meng-Chin LeE 2 \\ ${ }^{1}$ Department of Psychiatry, Taichung Hospital, Ministry of Health and Welfare, Taichung, Taiwan. \\ 2 Taichung Hospital, Ministry of Health and Welfare, Taichung, Taiwan.
}

Tsai LH, Lee MC / Arch Clin Psychiatry. 2016;43(6):157-8

Received: 7/5/2016 - Accepted: 11/10/2016

DOl: 10.1590/0101-60830000000104

\section{Dear Editor,}

The World Health Organization classifies depression as one of the top three diseases of the $21^{\text {st }}$ century, along with cardiovascular disease and cancer. Depression is a mental illness that requires significant attention in elderly patients ${ }^{1}$. Symptoms of major depression, internal and surgical drug-induced factors, and the use of antidepressants and their side effects need to be monitored in elderly patients.

We examined the effects of antidepressant discontinuation in a 69-year-old woman with psychotic symptoms and depression. The subject provided informed consent, and patient anonymity was preserved. The patient's history, physical and neurological examination results, family history, and laboratory data were used in the diagnosis. Figure 1 shows the patient's hospital course.

The onset of symptoms was distinct and notable. These symptoms indicated a diagnosis of major depressive disorder with psychotic symptoms, together with multiple discomforts, mood-congruent delusion of being abducted, and a family history of depression ${ }^{2,3}$. The patient also had delirium based on the reduced awareness of her environment, disorientation, and perceptual disturbances that developed over a short period and fluctuated during the day, according to the criteria of the Confusion Assessment Method.

The delirium caused by the discontinuation of paroxetine was treated with low-dose quetiapine, which had less anticholinergic and rare extrapyramidal side effects, as hallucinations can be induced by paroxetine discontinuation in middle-aged women ${ }^{5}$. Similarly, the present case study shows that sudden discontinuation of long-term antidepressants can trigger psychosis. The severity of withdrawal from selective serotonin reuptake inhibitors appears to vary according to the half-life of the drug; that is, the shorter the half-life, the worse the discontinuation effects ${ }^{6,7}$.

The patient's antidepressant discontinuation syndrome (ADS) manifested flu-like symptoms, sensory disturbances, and hyperarousal. ADS can be rapidly extinguished by early reinstitution of non-anticholinergic antidepressant (e.g., citalopram) ${ }^{8}$. Although ADS is not life threatening, it can be distressing to the patient because it can be easily mistaken for symptoms of returning depression ${ }^{6,7}$. For elderly patients, ADS may continue for longer periods with more severe symptoms.

We report that the non-anticholinergic effects of citalopram and similar drugs such as escitalopram can significantly improve cognitive function in elderly patients with depression. Antidepressants with non-anticholinergic side effects can shorten hospitalization duration in patients with depression and allow them to return to the community earlier.

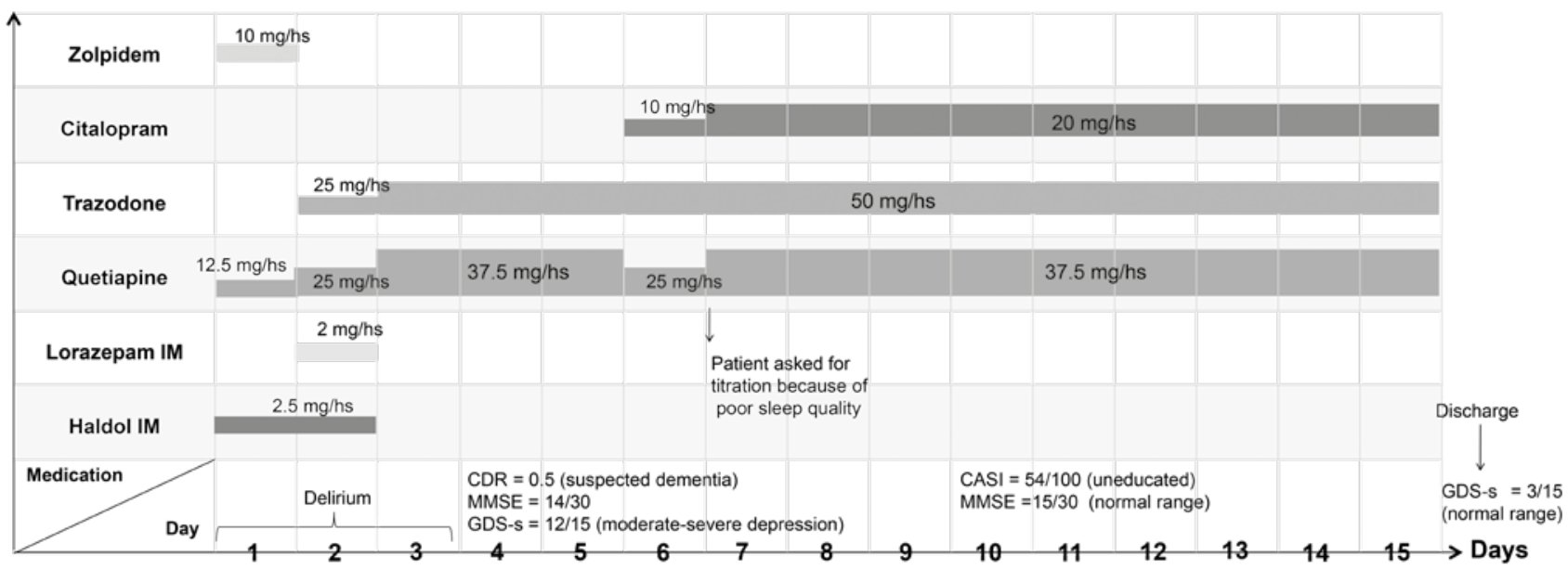

Figure 1. The patient's hospital course.

All medications were prescribed at bedtime to avoid drug-induced lethargy.

To keep the patient alert at daytime, she was allowed a refreshing sleep during the night.

Her medications were maintained from the seventh day of hospitalization because her mental status improved without any complaints.

The results of the two MMSEs showed no significant difference because of the floor effect on the population with low educational levels.

hs: at bedtime; CDR: clinical dementia rating; MMSE: Mini-Mental Status Examination; GDS-s: Geriatric Depression Scale-Short form; $\mathrm{IM}$ : intramuscular injection. 


\section{Conflict of interests}

No conflict of interests are reported.

\section{References}

1. Luchesi BM, Degani GC, Brígola AG, Pavarini SCI, Marques S. Evaluation of depressive symptoms in older caregivers. Arch Clin Psychiatry. 2015;42(2):45-51.

2. Hwang JP. Textbook of Clinical Geriatric Psychiatry. Taipei: Ho-Chi Book Publishing; 2011. Chapters 5-7.

3. Sadock BJ, Sadock VA. Kaplan \& Sadock's Synopsis of Psychiatry: Behavioral Sciences/Clinical Psychiatry. Philadelphia (PA): Lippincott Williams \& Wilkins; 2007. Chapters 5-6.
4. Dening T, Thomas A, editors. Oxford Textbook of Old Age Psychiatry. Oxford: Oxford University Press; 2008. Chapter 28.

5. Yasui-Furukori N, Kaneko S. Hallucination induced by paroxetine discontinuation in patients with major depressive disorders. Psychiatry Clin Neurosci. 2011;65(4):384-5.

6. Marken PA, Munro JS. Selecting a selective serotonin reuptake inhibitor: clinically important distinguishing features. Prim Care Companion J Clin Psychiatry. 2000;2(6):205-10.

7. PubMed Central [Internet]. Bethesda MD: National Institutes of Health's National Library of Medicine (NIH/NLM). 2016. Available from: http:// www.ncbi.nlm.nih.gov/pmc/.

8. Warner $\mathrm{CH}$, Bobo W, Warner C, Reid S, Rachal J. Antidepressant discontinuation syndrome. Am Fam Physician. 2006;74(3):449-56. 